\title{
Patotipos de Escherichia coli causadores de diarreia em bezerros: uma atualização ${ }^{1}$
}

\author{
Fernanda M. Coura ${ }^{2}$, Andrey P. Lage ${ }^{2}$ e Marcos B. Heinemann ${ }^{2,3 *}$
}

\begin{abstract}
Coura F.M., Lage A.P. \& Heinemann M.B. 2014. [Escherichia coli pathotypes associated with diarrhea in calves: an update.] Patotipos de Escherichia coli causadores de diarreia em bezerros: uma atualização. Pesquisa Veterinária Brasileira 34(9):811-818. Departamento de Medicina Veterinária Preventiva e Saúde Animal, Faculdade de Medicina Veterinária da Universidade de São Paulo, Av. Prof. Dr. Orlando Marques de Paiva 87, Cidade Universitária, São Paulo, SP 05508-270, Brazil. E-mail: marcosbryan@usp.br

Diarrhea is one of the most frequent diseases in calves up to 30 days of age and is a major cause of economic losses. Its etiology is complex and involves the interaction of various infectious, nutritional, immunological, environmental and managerial factors. The main clinical signs are diarrhea, progressive dehydration, metabolic acidosis, electrolyte imbalance and negative energy balance with or without hypoglycemia, which if left untreated, results in death of the animal. Escherichia coli stands as an important enteropathogen involved in diarrheal syndrome. Pathogenic E. coli strains are classified into groups or pathotypes based on the production of virulence factors and on the mechanisms by which they cause diarrhea. There are five E. coli pathotypes associated with diarrhea in calves: enterotoxigenic E. coli (ETEC), enteropathogenic E. coli (EPEC), enterohemorrhagic E. coli (EHEC), Shiga toxin - producing E. coli (STEC) and necrotoxigenic E. coli (NTEC). In this article, we present the main characteristics and an update on E. coli pathotypes causing calf diarrhea.
\end{abstract}

INDEX TERMS: Pathotypes, Escherichia coli, calves, diarrhea.

RESUMO.- A diarreia é uma das doenças mais frequentes de bezerros com até 30 dias de idade e é uma importante causa de perdas econômicas. Sua etiologia é complexa e envolve a interação de diversos fatores infecciosos, nutricionais, imunológicos, gerenciais e ambientais. Os principais sinais clínicos são a diarreia, desidratação progressiva, acidose metabólica, desequilíbrio de eletrólitos e balanço energético negativo com ou sem hipoglicemia, que se não tratados, levam à morte do animal. Escherichia coli se des-

\footnotetext{
${ }^{1}$ Recebido em 19 de agosto de 2013.

Aceito para publicação em 27 de abril de 2014.

${ }^{2}$ Departamento de Medicina Veterinária Preventiva, Escola de Veterinária da Universidade Federal de Minas Gerais (UFMG), Av. Antonio Carlos 6627, Campus Pampulha, Belo Horizonte, MG 30161-970, Brasil.

${ }^{3}$ Departamento de Medicina Veterinária Preventiva e Saúde Animal, Faculdade de Medicina Veterinária e Zootecnia da Universidade de São Paulo (USP), Av. Prof. Dr. Orlando Marques de Paiva 87, Cidade Universitária, São Paulo, SP 05508-270, Brasil. *Autor para correspondência: marcosbryan@usp.br
}

taca como um importante enteropatógeno envolvido na síndrome diarreica. Cepas de E. coli patogênicas são classificadas em grupos ou patotipos, de acordo com a produção de fatores de virulência e mecanismos pelos quais causam doença. Já foram identificados cinco patotipos de E. coli associados à diarreia em bezerros: $E$. coli enterotoxigênica (ETEC), E. coli enteropatogênica (EPEC), E. coli enterohemorrágica (EHEC), E. coli produtora de toxina Shiga (STEC) e E. coli necrotoxigênica (NTEC). Nesse artigo apresentamos as principais características e os atuais conhecimentos sobre os patotipos de E. coli causadores de diarreia em bezerros.

TERMOS DE INDEXAÇÃO: Patotipos, Escherichia coli, bezerros, diarreia.

\section{INTRODUÇÃO}

A diarreia é uma das doenças mais prevalentes em bezerros, principalmente nas quatro primeiras semanas de vida. 
É causa de importantes perdas econômicas nessa faixa etária, pois causa perda de água e eletrólitos nesses animais, o que resulta em desidratação, desequilíbrios eletrolíticos, acidose metabólica e morte (Butler \& Clarke 1994). Vários fatores de risco influenciam a ocorrência da doença, como idade do animal, condição imunológica, condições climáticas e higiene (Acres 1985, Radostits et al. 2007). Diversos enteropatógenos podem causar diarreia, com destaque para Escherichia coli, agente etiológico da colibacilose (Butler \& Clarke 1994, Blanchard 2012).

E. coli são bactérias Gram negativas, fermentativas, anaeróbias facultativas, cultivadas facilmente em meios de cultura de rotina. A via de transmissão de E. coli diarreiogênica é fecal-oral por meio de água e alimentos contaminados. Comumente isoladas de fezes, na maioria das vezes $E$. coli são comensais, não causando doença em seus hospedeiros. Entretanto, em animais debilitados, imunocomprometidos ou com a barreira gastrointestinal alterada, cepas de $E$. coli não patogênicas presentes no intestino podem causar infecção (Nataro \& Kaper 1998). Desta forma, para confirmação de diarreia por E. coli, é necessária a identificação de cepas de E. coli diarreiogênicas (Nataro \& Kaper 1998, Gyles \& Fairbrother 2010).

Antes da identificação de fatores de virulência específicos de E. coli diarreiogênicas, a sorotipagem era o método mais utilizado para identificar cepas associadas à diarreia. A determinação dos sorogrupos e sorotipos de E. coli a partir da identificação dos antígenos somáticos $(0)$, capsulares $(\mathrm{K})$ e flagelares $(\mathrm{H})$ são importantes para a caracterização de isolados associados às infecções e para estudos epidemiológicos. Os antígenos fimbriais (F), estruturas proteicas que se projetam da superfície da bactéria e permitem sua fixação à mucosa intestinal, também são utilizadas na classificação de cepas de E. coli, principalmente as denominadas E. coli enterotoxigênicas (ETEC) (Nataro \& Kaper 1998). E. coli de determinados sorogrupos podem ser associadas a síndromes clínicas, pois estes sorogrupos correlacionam-se com certas linhagens virulentas e grupos específicos de E. coli diarreiogênicas. Entretanto, a sorotipagem é trabalhosa e realizada por poucos laboratórios, além desses marcadores não serem suficientes para caracterizar uma cepa como diarreiogênica (Nataro \& Kaper 1998).

Como na maioria dos patógenos de mucosa, E. coli segue uma estratégia de infecção: i) colonização da mucosa, ii) evasão das defesas do hospedeiro, iii) multiplicação e iv) dano ao hospedeiro. E. coli causadoras de infecções enté- ricas em geral apresentam diferentes sorotipos e fatores de virulência. A colonização das células intestinais ocorre por meio de adesinas, que podem ser fimbriais ou não. A produção de diversas toxinas, que interagem com os enterócitos de maneiras diferentes, também é uma característica comum de cepas diarreiogênicias de E. coli. Algumas cepas de E. coli interagem com o citoesqueleto das células intestinais, modificando a estrutura das microvilosidades das células das vilosidades intestinais. Esses fatores de virulência são codificados por genes presentes em ilhas de patogenicidade ou em plasmídeos de virulência, podendo também ser transferidos entre cepas de E. coli por bacteriófagos. Atualmente, a identificação de genes de virulência por PCR têm demonstrado ser rápida, prática e sensível na identificação de E. coli diarreiogênicas (Nataro \& Kaper 1998, Gyles \& Fairbrother 2010).

As cepas de E. coli consideradas patogênicas podem ser classificadas em grupos ou patotipos de acordo com a produção de fatores de virulência e mecanismos pelos quais causam doença (Nataro \& Kaper 1998, Kaper et al. 2004). As características dos principais patotipos de E. coli causadores de diarreia em bezerros são mostrados no Quadro 1 . Já foram identificados cinco patotipos de E. coli associados à diarreia em bezerros: $E$. coli enterotoxigênica (ETEC), $E$. coli enteropatogênica (EPEC), E. coli enterohemorrágica (EHEC), E. coli produtora de toxina Shiga (STEC) e E. coli necrotoxigênica (NTEC). Outros patotipos diarreiogênicos para seres humanos, como $E$. coli enteroinvasiva (EIEC), $E$. coli de aderência difusa (DAEC) e E. coli enteroagregativa (EAEC) ainda não foram confirmados como causadores de diarreia em bezerros (Nataro \& Kaper 1998, DebRoy \& Maddox 2001, Gyles \& Fairbrother 2010). Nessa revisão apresentamos as principais características e os atuais conhecimentos sobre os mais importantes patotipos de E. coli causadores de diarreia em bezerros.

\section{PATOTIPOS DE E. coli CAUSADORAS DE DIARREIA EM BEZERROS}

\section{Escherichia coli enterotoxigênica (ETEC)}

ETEC são caracterizadas por colonizarem a superfície da mucosa do intestino delgado, principalmente o íleo, e por produzirem enterotoxinas termoestáveis (ST) e termolábeis (LT) que alteram as funções dos enterócitos, aumentando a secreção e reduzindo a absorção de líquidos, sem induzirem alterações morfológicas significativas no intestino (Nataro \& Kaper 1998, Nagy \& Fekete 2005).

Quadro 1. Principais características dos patotipos de Escherichia coli causadores de diarreia em bezerros

\begin{tabular}{|c|c|c|c|}
\hline \multirow[t]{2}{*}{ Patotipo } & \multicolumn{2}{|c|}{ Fatores de virulência } & \multirow[t]{2}{*}{ Sorogrupos } \\
\hline & Adesina & Toxina & \\
\hline ETEC $^{a}$ & F5, F41, F17 e CS31A & STa & $08,09,020,0101$ \\
\hline EPEC $^{b}$ & Intimina, Lpf, Iha, Efa1, ToxB & - & 026, 0111, 0119, 0114 \\
\hline STEC $^{c}$ & Saa, ToxB, Lpf, Iha & Stx1, Stx2 & 08,020 \\
\hline EHEC $^{\mathrm{d}}$ & Intimina, Efa 1, ToxB, Lpf, F9, Iha & Stx1, Stx2, Ehx & 05, 026, 0111, 0118, 0145 \\
\hline NTEC $^{\mathrm{e}}$ & $\mathrm{P}, \mathrm{S}, \mathrm{F} 17, \mathrm{Afa}$ & CNF1, CNF2 & $01,03,015,088,0123$ \\
\hline
\end{tabular}


As toxinas termoestáveis são denominadas STaP, STaH e STb. STaP e STaH (ou STI) possuem 18 e 19 aminoácidos, respectivamente, com um peso molecular de menos de 2 $\mathrm{kDa}$, enquanto STb (ou STII) possui 48 aminoácidos e tem um peso molecular de $5 \mathrm{kDa}$. STaP é produzida por ETEC de animais (bovinos, ovinos, suínos e caninos) e seres humanos, e STaH por ETEC de seres humanos. STb é encontrada em ETEC isoladas de suínos (Mainil 2013).

Dois tipos de toxinas LT são produzidas, LTI e LTII. LTI pode ser subdividida em LTIh, de ETEC de seres humanos, e LTIp, de ETEC de suínos e seres humanos. LT-IIa e LT-IIb são produzidas por ETEC isoladas de seres humanos e, com menor frequência, de bovinos e bubalinos. LT ativa adenilato ciclase, resultando no aumento dos níveis de monofosfato cíclico de adenosina (AMPc) e, consequentemente, aumento da secreção de íons cloreto e carbonato, de água e na inibição da absorção de sódio (Mainil 2013).

A maioria das ETEC que causam diarreia em bezerros é caracterizada por possuir as adesinas fimbriais F5 (K99) e F41 e por produzir STa. Outras adesinas menos frequentes em ETEC isoladas de bezerros são F17 e CS31A (não fimbrial) (Quadro 1) (Butler \& Clarke 1994, DebRoy \& Maddox 2001). Os sorogrupos mais comuns entre as ETEC associadas à diarreia em bezerros são 08, 09, 020 e 0101 (Butler \& Clarke 1994).

A adesão de ETEC no intestino delgado ocorre por fatores de colonização, fimbriais ou não fimbriais (Croxen \& Finlay 2010). A ligação da ETEC ao epitélio intestinal impede que estas bactérias sejam totalmente eliminadas pelo peristaltismo e permite a colonização do intestino, principalmente a parte distal do intestino delgado. Em seguida a aderência às células intestinais, ETEC produzem enterotoxina STa (Gyles \& Fairbrother 2010). O receptor de STa é a guanilato ciclase $\mathrm{C}$ (GC-C), presente nas microvilosidades intestinais. A ligação da toxina no receptor resulta no aumento intracelular de monofosfato guanilato cíclico (cGMP), que ativa a proteína quinase II cGMP-dependente (cGKII). Essa quinase fosforila e ativa o canal de cloreto (CFTR), o que resulta na secreção de íons cloreto e bicarbonato, na inibição da absorção de íons sódio e no efluxo de água para o lúmen intestinal (Foster \& Smith 2009, Gyles \& Fairbrother 2010).

As infecções por ETEC são espécie-específicas principalmente em função da presença de receptores específicos para adesinas em células intestinais de uma ou de um número limitado de espécies, não sendo, portanto, consideradas como zoonóticas, em contraste com as infecções por EHEC e STEC (Nagy \& Fekete 2005).

ETEC é o patotipo mais comumente associado à diarreia em bezerros na primeira semana de vida, principalmente aos 3-4 dias (Foster \& Smith 2009, Blanchard 2012). Diversos pesquisadores encontraram esse patotipo em bezerros com mais de uma semana de idade (Güler et al. 2008, Bartels et al. 2010, Coura 2011, Andrade et al. 2012). A razão da restrição da infecção por ETEC à primeira semana de idade dos bezerros não é totalmente conhecida. Os receptores para as fímbrias são mais expressos em células imaturas das vilosidades intestinais. Assim, a maturação intestinal pós-natal limita a infecção por ETEC em bezerros com menos de uma semana de idade. Entretanto, pode haver aumento do período de susceptibilidade se ocorrer atrofia das vilosidades intestinais, como acontece nas infecções por vírus e Cryptosporidium spp., resultando em migração de células imaturas das criptas (Blanchard 2012).

Sabe-se que em ratos e seres humanos a densidade do receptor GC-C diminui após o nascimento, mas permanece presente em suínos até 7 semanas de vida. Em bezerros nenhum estudo detalhado sobre a expressão de GC-C em diferentes idades foi realizado, porém inoculação oral com STa induziu diarreia em bezerros com até 15 dias de idade (Foster \& Smith 2009).

Na colibacilose por ETEC, os animais apresentam diarreia profusa pastosa a líquida, com odor fétido e coloração amarelada a brancacenta. Nos casos agudos, a perda de água e eletrólitos é rápida, e os animais apresentam desidratação grave e acidose metabólica, podendo levar a morte. Observa-se a distensão dos intestinos delgado e grosso, com presença de líquido e gás, mucosa fina e brilhante e nenhuma alteração histopatológica. A síndrome diarreia é multifatorial e pode envolver mais de um enteropatógeno, dificultando o diagnóstico clínico. Mas a possível participação de ETEC na diarreia em bezerros pode ser sugerida pelos seguintes fatores: i) idade do animal inferior a uma semana, ii) característica das fezes, iii) desenvolvimento agudo da infecção, com grave diarreia e desidratação, animal em posição de decúbito e perda de peso. Para o diagnóstico de infecção por ETEC é necessário o isolamento bacteriano de fezes ou conteúdo intestinal e a identificação dos fatores de virulência característicos de ETEC, fímbrias e toxinas, utilizando testes laboratoriais como testes de aglutinação, ELISA ou PCR (Acres 1985, Butler \& Clarke 1994), todos disponíveis no país.

\section{E. coli enteropatogênica (EPEC)}

A principal característica deste patotipo é causar uma lesão denominada de attaching and effacing - A/E. A lesão A/E é caracterizada por uma adesão íntima da bactéria ao epitélio intestinal, com destruição das microvilosidades intestinais, alterações no citoesqueleto, com formação de estruturas semelhantes a pedestais e acúmulo de actina polimerizada logo abaixo da ligação da bactéria à célula. Os principais genes responsáveis pela lesão A/E estão inseridos numa ilha de patogenicidade denominada LEE (Locus of Enterocyte Effacement), presente nos patotipos EPEC e EHEC (Nataro \& Kaper 1998, Mainil \& Daube 2005). E. coli capazes de causar esse tipo de lesão são também denominadas AEEC (attaching and effacing Escherichia coli).

EPEC coloniza principalmente o intestino delgado e sua aderência nas microvilosidades intestinais desencadeia a expressão dos genes localizados na LEE. Após sua ligação com a célula hospedeira, há o envio de sinais para estas por meio de um sistema de secreção tipo III (T3SS), cujos genes estão localizados na LEE. O T3SS, inserido na membrana citoplasmática do enterócito, transloca diretamente proteínas efetoras da bactéria para dentro do citoplasma da célula do hospedeiro. Estas proteínas efetoras agem em proteínas celulares eucarióticas resultando na polimerização da actina, rearranjos do citoesqueleto e destruição das 
microvilosidades (DebRoy \& Maddox 2001, Mainil \& Daube 2005, Mainil 2013).

A adesina intimina, uma proteína de $94 \mathrm{kDa}$ da membrana externa da bactéria, é codificada pelo gene eae localizado na LEE e é a molécula de adesão responsável pela ligação íntima da bactéria ao enterócito. 0 receptor da célula alvo para intimina recebe o nome de Tir (translocated intimin receptor), uma proteína codificada pela LEE, translocada para a célula alvo pelo T3SS e que se insere na membrana citoplasmática do enterócito (Mainil \& Daube 2005, Mainil 2013). Mais de 21 variantes de intimina já foram identificadas, designadas por letras gregas, e que diferem na sua sequência de aminoácidos na parte carboxi-terminal. Uma vez que a interação entre intimina e Tir está localizada no aminoácido caboxi-terminal 280 da adesina intimina, os diferentes tipos de intimina interagem especificamente com o seu receptor cognato Tir. Receptores alternativos para intimina na célula hospedeira são as beta1-integrinas e as nucleolinas (Gyles \& Fairbrother 2010, Mainil 2013). A proteína Tir fosforilada recruta Nck (non-catalytic region of tyrosine kinase) que ativa a proteína da síndrome neural Wiskott-Aldrich (N-WASP) e o complexo de proteína $2 / 3$ relacionado à actina (ARP2/3) para mediar o rearranjo de actina e formação das estruturas semelhantes a pedestal (Croxen \& Finlay 2010).

Além da ilha de patogenicidade LEE, EPEC podem apresentar um plasmídeo chamado "EPEC aderence factor" (EAF), com genes envolvidos na expressão e montagem da fímbria denominada "bundle-forming pillus" (BFP), responsável pela aderência localizada da bactéria ao epitélio intestinal. Cepas de EPEC portadoras do plasmídeo EAF e da fímbria BFP são denominadas EPEC típicas, e quando negativas EPEC atípicas. A adesina BFP contribui para a ligação da bactéria às células eucarióticas e resulta em aderência localizada em cultura de células (Nataro \& Kaper 1998, Bardiau et al. 2010, Gyles \& Fairbrother 2010). No caso de EPEC isoladas de bezerros, BFP não foi identificada e outras adesinas podem estar envolvidas na aderência e, provavelmente, na colonização das células intestinais, como Iha (IrgA Homologue Adhesin), Efa1 (E. coli factor for adherence 1), ToxB (toxin B) e Lpf (long polar fimbriae) (Quadro 1) (Bardiau et al. 2010).

Não há uma faixa etária com maior susceptibilidade, como ocorre com ETEC, sendo detectada a infecção por EPEC em bezerros de 1 a 12 semanas de idade (China et al. 1998, Holland et al. 1999, Foster \& Smith 2009). Os principais sorotipos de EPEC associados à diarreia em bezerros são 026, 0111, 0119, 0114. EPEC causa diarreia pela ativação de sistemas secretórios, como a inibição da absorção de sódio e cloreto e ativação dos canais de cloreto, aumento da permeabilidade paracelular, afrouxamento das junções de oclusão (tight junctions), inflamação e produção de citocinas, e perda da área absortiva em decorrência da destruição das microvilosidades (Mainil \& Daube 2005, Gyles \& Fairbrother 2010).

O diagnóstico clínico é difícil, sendo que não existem sinais clínicos característicos. A consistência e a cor das fezes variam. As fezes podem estar aquosas ou normais, amareladas ou sanguinolentas. EPEC resulta em uma diarreia mais crônica, diferente da ocorrência aguda da colibacilose por ETEC, e ocorre principalmente em animais acima de uma semana de idade. 0 diagnóstico histopatológico de partes do íleo (principalmente junção ileocecal) e cólon pode ser usado para visualizar lesões do tipo A/E. A confirmação da presença de EPEC é feita a partir da cultura de fezes seguida por PCR para identificação dos genes de virulência característicos desse patotipo, principalmente o eae, e confirmar a ausência de genes codificadores de toxinas, necessário para diferenciar cepas de EPEC de STEC/EHEC (Nataro \& Kaper 1998, DebRoy \& Maddox 2001, Blanchard 2012).

\section{E. coli enterohemorrágica (EHEC) e E. coli produtora de toxina Shiga (STEC)}

E. coli enterohemorrágica (EHEC) e E. coli produtora de toxina Shiga toxina (STEC), também conhecida como E. coli verotoxigênica (VTEC), em função do efeito citotóxico em células Vero, se referem a cepas de E. coli que produzem pelo menos umas das toxinas Shiga (Stx1 ou Stx2) (Gyles 2007). Outro fator de virulência importante para a caracterização de EHEC é a presença da ilha de patogenicidade LEE (locus of enterocyte effacement), com genes responsáveis pela formação de A/E, como em EPEC. EHEC possui a mesma LEE de EPEC, porém o mecanismo de formação da estrutura semelhante ao pedestal é ligeiramente distinto das EPEC: não ocorre fosforilação de Tir pela célula hospedeira, a formação de pedestal é independente de Nck, o rearranjo de actina é mediado por TccP (Tir cytoskeleton-coupling protein), que se liga ao Tir por meio de proteínas da célula alvo IRTKS (insulin receptor tyrosine kinase substrate), que interage com N-WASP para ativar o complexo ARP2/3 (Croxen \& Finlay 2010).

Durante muito tempo o termo EHEC foi utilizado para se referir a isolados de $E$. coli que causam doenças em seres humanos, como colite hemorrágica e síndrome hemolítica urêmica, mas hoje EHEC inclui cepas de E. coli isoladas de seres humanos e animais que produzem toxinas Stx e lesão A/E. Já os termos STEC ou VTEC são usados para isolados de bactérias que produzem somente Stx (Mainil \& Daube 2005). Alta porcentagem de bezerros infectados com estes patotipos não apresenta sinais clínicos, entretanto estes animais constituem importante reservatório de STEC/ EHEC tanto para bovinos como para o homem (Gyles \& Fairbrother 2010). Em 2011, houve uma grande epidemia causada por um sorotipo raro de E. coli patotipo STEC e sorotipo 0104:H4, envolvendo mais de 4.000 pessoas em 16 países europeus.. Estudos epidemiológicos indicaram o consumo de brotos, principalmente os de feno-grego, como a origem do surto (CDC 2013). A análise genética do isolado demonstrou que ele pertence a dois grupos distintos de E. coli, EAEC e STEC, e foi classificado como STEAEC, por possuir genes de ambos os patotipos e de múltipla resistência a antibióticos. 0 cromossomo possui os fatores de virulência Pic, AAF, AggR, Pet e ShET1 de EAEC, e Stx2 e Iha de STEC (Clements et al. 2012). 0 sorotipo de EHEC mais conhecido e de maior importância para seres humanos é o 0157:H7, responsável por surtos de diarreia sanguinolenta, colite hemorrágica e síndrome hemolítico urêmica. E. coli $0157: \mathrm{H} 7$ é a principal causa de colite hemorrágica 
e síndrome hemolítico urêmica nos Estados Unidos, Canadá, Grã-Bretanha e Europa (Buchanan \& Doyle 1997). No Brasil, a incidência de doenças gastrointestinais e síndrome hemolítico urêmica devido a EHEC 0157:H7 é baixa e a frequência de seu isolamento de fezes bovinas é ausente, ou muito baixa, menos de $1 \%$ dos isolados (Cerqueira et al. 1999, Irino et al. 2005, Aidar-Ugrinovich et al. 2007, Oliveira et al. 2008) e de carcaças bovinas resfriadas ainda não foi isolada (Caselani 2010).

Os ruminantes, especialmente os bovinos, são portadores assintomáticos e considerados principais reservatórios de EHEC (Gyles 2007). Surtos de infecção por EHEC estão associados ao consumo de vários tipos de alimentos como hambúrgueres mal cozidos, salsichas, leite não pasteurizado, alface, e suco de maçã. A dose infectante é baixa, menos de 100 células bacterianas, facilitando a infecção. Stx produzida no cólon cai na corrente sanguínea e vai para o rim, danificando células endoteliais e resultando em inflamação renal. 0 dano renal pode resultar em síndrome hemolítico urêmica, caracterizada por uma anemia hemolítica, trombocitopenia e insuficiência renal aguda. Stx também danifica o cólon, resultando em diarreia sanguinolenta e colite hemorrágica (Kaper et al. 2004).

EHEC não possui um sistema de secreção para Stx, a liberação da toxina ocorre por meio de lise do fago que codifica a toxina em reposta a danos no DNA bacteriano, por isso antimicrobianoterapia não deve ser usada em infecções por EHEC, pois aumenta a liberação da toxina agravando a síndrome (Croxen \& Finlay 2010) Existem hoje três subtipos de Stx1 (Stx1a, Stx1c, Stx1d) e sete subtipos de Stx2 (Stx2a, Stx2b, Stx2c, Stx2d, Stx2e, Stx2f, Stx2g), sendo que as cepas produtoras de Stx2a, Stx2c e ou Stx2d são mais frequentemente associadas com a síndrome hemolítica urêmica em seres humanos. As cepas de E. coli produtoras de Stx2e são de grande importância em suinocultura, pois causam a doença do edema em suínos (Mainil 2013). Os genes que codificam Stx estão presentes e são transferidos por bacteriófagos para as cepas de E. coli. As Stx possuem uma estrutura do tipo A1B5, onde as cinco subunidades $B$ são responsáveis pela ligação da toxina à célula alvo e a subunidade A é o componente ativo da toxina. 0 receptor para Stx é o Gb3 (globotriaosylceramide), presente nas células de Paneth da mucosa intestinal e nas células epiteliais dos rins de seres humanos, ou Gb4 (globotetraosylceramide) para Stxe, presente no endotélio vascular e enterócitos de suínos. A toxina Stx pode atravessar o epitélio intestinal por meio de endocitose seguido por exocitose na parte basal do enterócito, mas o mecanismo não está totalmente elucidado. Em seres humanos e leitões, a Stx cai na corrente sanguínea e se une aos receptores endoteliais. As Stx agem em células endoteliais dos vasos sanguíneos da mucosa gastrointestinal, dos rins, do cérebro e outros tecidos, causando extravasamento de líquido, hemorragias, a nefrotoxicidade observada em seres humanos e a neurotoxicidade observada em leitões com doença do edema. Ruminantes não possuem esses receptores para Stx no endotélio vascular, mas os mesmos estão presentes nos enterócitos das criptas, linfócitos intraepiteliais e macrófagos da mucosa intestinal. EHEC/STEC também podem colonizar o intesti- no dos ruminantes, embora não causem lesões vasculares e, por isso, sinais sistêmicos não são observados. Após a entrada da toxina na célula, a subunidade A remove uma adenina do rRNA $28 \mathrm{~S}$ do ribossomo eucariótico, alterando sua função e resultando em inibição da síntese proteica, o que é letal para a célula (Mainil \& Daube 2005, Croxen \& Finlay 2010, Mainil 2013).

A infecção oral com EHEC 0118 (eae/stx1) em bezerros resulta em diarreia e em lesões A/E no final do intestino delgado e intestino grosso 24 horas pós-infecção (Stordeur et al. 2000). Girard et al. (2007) utilizaram explantes de intestino bovino cultivados in vitro (bIVOC) para estudar a infecção por E. coli dos sorogrupos 0157 (Stx1, Stx2 e eae), 026 (Stx1 e eae) e 0111 (Stx1) e demonstraram que todos os três sorogrupos aderiram intimamente ao epitélio do íleo terminal, do cólon e do reto e produziram lesões A/E típicas, menos no cólon terminal, onde as lesões foram menos evidentes.

Apesar de alguns autores considerarem a diarreia como consequência da formação da lesão A/E e não da produção de qualquer Stx, existe associação experimental e epidemiológica de STEC com diarreia em bezerros (Mainil \& Daube 2005, Mainil 2013). Outros fatores de virulência já foram detectados em STEC/EHEC isoladas de bezerros, como as adesinas F9, Iha (IrgA Homologue Adhesin), Saa (STEC autoagglutinating adhesin), Toxb (Toxin B), Lpf (Long polar fimbriae) e Efa1 (E. coli factor for adherence 1) (Quadro 1) (Bardiau et al. 2010). A enterohemolisina (Ehx) já foi detectada em STEC/EHEC. Ehx pertence à família de toxinas RTX e sua ação resulta na formação de poros nas células alvo, mas sua contribuição na etiologia da diarreia por esses patotipos não é totalmente conhecida (Mainil \& Daube 2005, Mainil 2013).

Os principais sorotipos de EHEC associados à diarreia em bezerros são 05, 026, 0111, 0118 e 0145, e de STEC 08 e 020 (Mainil \& Daube 2005). EHEC e STEC estão associadas à diarreia em bezerros com duas a oito semanas de idade (Butler \& Clarke 1994). Apesar de não haver sinais clínicos muito característicos desses patotipos, é relatada, ao contrário do que acontece com infecções por ETEC, uma diarreia menos aquosa, com aspecto mucóide, às vezes sanguinolenta e com tendência à cronicidade, com os animais menos desidratados e raramente causando sua morte $(\mathrm{Bu}-$ tler \& Clarke 1994, DebRoy \& Maddox 2001).

Animais afetados por EHEC apresentam lesões A/E no íleo terminal, cólon e reto, com edema e infiltrado neutrofílico na lâmina própria (DebRoy \& Maddox 2001, Gyles \& Fairbrother 2010). A identificação de EHEC/STEC pode ser feita utilizando PCR para detecção dos principais genes de virulência, testes de citotoxicidade em células e ELISA para pesquisa das toxinas Shiga (DebRoy \& Maddox 2001, Blanchard 2012).

\section{E. coli necrotoxigênica (NTEC)}

NTEC são caracterizadas pela produção de toxinas CNF (fator necrotizante citotóxico) (De Rycke et al. 1999). A existência de dois tipos de CNF, tipo 1 e tipo 2 (CNF1 e CNF2), foi demonstrada em cepas de E. coli isoladas de bezerros, leitões e crianças com enterite (De Rycke et al. 1990). Am- 
bos os tipos de citotoxinas são letais para camundongos quando inoculadas via intraperitoneal, compartilham a capacidade de induzir células gigantes multinucleadas em linhagem de células HeLa e necrose em pele de coelho, e são parcialmente relacionadas antigenicamente. Porém somente CNF2 induz necrose em pata de camundongo e produz acúmulo de fluido no teste da alça ligada de coelho (De Rycke et al. 1990). Uma nova toxina necrotizante, denominada CNF3, foi identificada em isolados de E. coli obtidas de ovinos e caprinos (Orden et al. 2007). Os autores para identificar a CNF3, clonaram e sequenciaram o gene cnf3 presente em uma cepa de NTEC denominada C48a (0153:H11) isolada de uma ovelha saudável e, por meio da PCR, identificaram o gene em cepas isoladas das fezes de caprinos e ovinos (Orden et al. 2007).

0 gene codificador para CNF1 está localizado em uma ilha de patogenicidade cromossomal, entre os genes de alfa hemolisina (hly) e os genes codificadores de adesinas $\mathrm{P}$ (pap/prs). 0 gene codificador para CNF2 está no plasmídeo Vir, que também contém genes para outros fatores de virulência como a toxina distensora citoletal tipo 3 (CDTIII), adesina Afa-VIII, fímbria F17 e hemolisina (De Rycke et al. 1999, Johnson et al. 2010). É comum encontrar esses e outros fatores de virulência em conjunto com CNF: CNF1 pode ser encontrada juntamente com hemolisina, fímbrias P, fímbrias S, F17 e adesinas afimbriais Afa e CNF2 com F17, Afa e CDTIII (Quadro 1) (Mainil 2013). Outro fator de virulência presente em NTEC, e também em isolados de ETEC, de STEC e de E. coli que causam infecções extraintestinais, é a alfa hemolisina, porém seu papel na patogênese da diarreia ainda é incerto (Mainil 2013).

CNF e outros fatores de virulência foram pesquisados em cepas de $E$. coli isoladas de fezes de bezerros e filhotes de cães com e sem diarreia e de urina coletada de cães adultos com cistite (Salvarani et al. 2012). CNF foi identificada em $E$. coli de ambas as espécies, em casos de diarreia e cistite, conjuntamente com os fatores de virulência hemolisina, fímbria P, fímbria $S$, fímbria tipo 1 e toxina distensora citoletal. Nos isolados obtidos de bovinos, todas as cepas positivas para o gene $c n f 2$ foram positivas para $c d t$-iii.

As toxinas CNF induzem a desaminação de membros da família das Rho GTPases: Glutamina 63 (Gln63) de Rho e, Gln61 de Rac e Cdc42. Isto impede a hidrólise de GTP e resulta na ativação permanente da proteína. A ativação de Rho resulta na formação de fibras de estresse, que são feixes de filamentos espessos paralelos contráteis de actina. A ativação de Rac conduz à formação de lamelipódio, estruturas bidimensionais semelhantes a camadas ou lençóis contendo uma rede de filamentos de actina interligados ortogonalmente. CNF também induz formação de filopódio em decorrência da ativação de Cdc42, estruturas unidimensionais que contêm um núcleo de longos filamentos de actina em feixe. Além do achatamento do corpo da célula decorrente da ativação das Rho GTPases, as células se tornam multinucleadas (Alberts et al. 2010, Knust \& Schmidt 2010).

Em células T84 (células de carcinoma colorretal humano), CNF1 ativa Rho, Rac e Cdc42, aumenta a permeabilidade paracelular e induz reestruturação e reorganização das proteínas das junções de oclusão (ocludina, ZO-1, JAM-1) assim como de F-actina (Hopkins et al. 2003). Em células Caco-2 (células de carcinoma de cólon humano) foram verificados também a ativação de Rho GTPases e a diminuição da resistência transepitelial (Blumenthal et al. 2007). Desta forma a ativação de Rho GTPases parece estar envolvida no surgimento da diarreia.

NTEC1 já foi isolada de diarreia em ruminantes, suínos, cães, coelhos e equinos, de septicemia em suínos, de infecções no trato urinário e outras infecções extra-intestinais em cães, gatos e seres humanos (Van Bost et al. 2001a). CNF1 também é um importante fator de virulência de UPEC (Escherichia coli uropatogênica). Ele está associado a vários outros fatores de virulência como aerobactina, fímbrias P e hemolisina. Quase todos os isolados de UPEC positivos para CNF1 contêm o gene para alfa hemolisina. CNF1 também já foi encontrada em $E$. coli isoladas de meningite em crianças (Boquet 2001, Knust \& Schmidt 2010).

NTEC2 já foi isolada de bovinos, caprinos, equinos e gatos (Pohl et al. 1993). NTEC2 tem sido isolada principalmente de ruminantes jovens com diarreia, mas também de septicemia, pneumonia, metrite e mastite em bovinos (Van Bost et al. 2001a). NTEC2 é o patotipo mais frequentemente isolado de bovinos com diarreia e septicemia (Burns et al. 1996). CNF3 foi identificada em E. coli isoladas de cordeiros com e sem diarreia e cabritos saudáveis (Orden et al. 2007). Os sorogrupos de NTEC2 mais frequentes em bovinos são 01, 03, 015, 088 e 0123 (Blanco et al. 1998, Orden et al. 1999).

Em um estudo realizado na Espanha, NTEC foi pesquisada em E. coli isoladas de 246 bezerros com diarreia. NTEC foi detectada por PCR nas fezes de 39 dos 246 animais diarreicos, sendo que 34 animais estavam infectados por NTEC positiva para cnf2 e 5 para cnf1. Além disso, foi encontrada uma associação entre a idade e a infecção por NTEC2, na qual o risco de infecção por NTEC em bezerros diarreicos aumenta com a idade, principalmente em animais com 31 a 90 dias de idade (Orden et al. 1999).

Estudos envolvendo NTEC produtora de CNF2 e utilizando bezerros recém-nascidos que não receberam colostro e desafiados oralmente demonstram que este patotipo é capaz de colonizar o intestino e causar diarreia, além de invadir a corrente sanguínea e ir para órgãos internos, principalmente os pulmões. À necropsia foram observadas congestão da mucosa intestinal, espessamento da mucosa do intestino delgado e congestão pulmonar. À histopatologia foram observadas enterocolite, linfadenite, atrofia de vilosidades do intestino delgado e broncopneumonia (Van Bost et al. 2001b, Van Bost et al. 2003).

A confirmação da diarreia causada por NTEC pode ser realizada pela identificação dos genes codificadores das CNF em isolados bacterianos obtidos de fezes e lesões intestinais ou outros órgãos, no caso de septicemia, utilizando a técnica de PCR, ou também por meio de testes de citotoxicidade em cultura de células (De Rycke et al. 1999, Orden et al. 1999).

\section{ESTUDOS EPIDEMIOLÓGICOS BRASIL}

Um estudo foi realizado no estado de São Paulo com o objetivo de determinar a prevalência de $E$. coli produtora de 
toxina Shiga (STEC) em isolados de animais com e sem diarreia. E. coli positiva para o gene Stx (toxina Shiga) foi encontrada em quarenta e quatro animais sendo $28(20 \%)$ com diarreia e $16(7,8 \%)$ saudáveis. Vinte e quatro isolados produziram a toxina Shiga, dos quais 12 foram positivos para o Stx1, oito para Stx1 e Stx2 e quatro para Stx2. Dez isolados foram positivos para o gene eae (Leomil et al. 2003).

Na região Centro-Oeste do Brasil, cepas de E. coli isoladas de bezerros com diarreia foram examinadas quanto à presença de fatores de virulência associados à colibacilose bovina. A toxina Stx1 foi detectada em 20 amostras, a Stx2 em 13 e a STa em oito. A adesina fimbrial F5 foi identificada em 15 isolados, dos quais quatro eram ETEC (F5/STa). A fímbria F41 não foi detectada e o gene eae foi identificado em sete amostras produtoras de toxina Shiga 1 (Stx1) (Salvadori et al. 2003).

Aidar-Ugrinovich et al. (2007) estudaram STEC e EPEC isoladas de bezerros no estado de São Paulo. Os patotipos STEC e EPEC foram isolados em $12 \%$ e 2,6\% dos casos com diarreia, respectivamente. Nos animais saudáveis, STEC e EPEC foram isoladas em 8,5\% e 2,8\% dos casos, respectivamente. Vinte seis por cento das STEC isoladas dos animais diarreicos e $25 \%$ das isoladas dos saudáveis, possuíam o gene eae.

Os estudos epidemiológicos realizados no Brasil indicam a presença dos patotipos associados à diarreia em bezerros, tanto em rebanhos de bovino de leite como de corte. Porém os resultados entre os estudos divergem, devido a diversos fatores como a região geográfica estudada, época do ano, número de animais e método de diagnóstico empregado. A frequência de ETEC varia desde zero até $30 \%$ (Lage et al. 1993, Mendonça et al. 1996, Langoni et al. 2004, Rigobelo et al. 2006, Oliveira Filho et al. 2007, Coura 2011, Moura et al. 2012, Andrade et al. 2012). EPEC varia desde $1,42 \%$ até $42,5 \%$ (Rigobelo et al. 2006, Aidar-Ugrinovoch et al. 2007, Coura 2011, Moura et al. 2012, Andrade et al. 2012) e STEC e EHEC varia entre 2,7\% até mais de $50 \%$ (Rigobelo et al. 2006, Aidar-Ugrinovoch et al. 2007, Coura 2011, Andrade et al. 2012).

Existem poucos trabalhos sobre a ocorrência de NTEC em bezerros no Brasil. Em um estudo realizado com amostras de E. coli isoladas de bezerros com diarreia na região Centro-Oeste do Brasil, CNF1 foi detectado em uma amostra e CNF2 em nove de duzentas e cinco amostras pesquisadas (Salvadori et al. 2003), indicando a presença do patotipo no Brasil.

\section{CONSIDERAÇÕES FINAIS}

Escherichia coli é um importante agente causador de diarreias em bovinos, mas apenas o isolamento e identificação da bactéria nos casos de diarreia não significam que este agente é o causador da patologia, para tanto há a necessidade de classificar os isolados em patotipos. Até o presente momento, já foram identificados cinco patotipos de E. coli associados a diarreia em bezerros: $E$. coli enterotoxigênica (ETEC), E. coli enteropatogênica (EPEC), E. coli enterohemorrágica (EHEC), E. coli produtora de toxina Shiga (STEC) e E. coli necrotoxigênica (NTEC), sendo que outros patotipos diarreiogênicos para seres humanos, como E. coli en- teroinvasiva (EIEC), $E$. coli de aderência difusa (DAEC) e $E$. coli enteroagregativa (EAEC) ainda não foram identificados como causadores de diarreia em bovinos. Além disso, os ruminantes são considerados os principais reservatórios de STEC/EHEC, importante patógeno para seres humanos. Deste modo é de fundamental importância o conhecimento sobre os patotipos e os fatores de virulência, bem como sua distribuição como agentes causadores de diarreia em bovinos.

A classificação dos isolados é importante para identificar tanto o patotipo envolvido na diarreia como a circulação de novos patotipos infectando bovinos. A vigilância e identificação dos diversos patotipos é de grande importância para o entendimento da relação hospedeiro parasita.

Agradecimentos.- Ao Conselho Nacional de Desenvolvimento Técnico e Científico (CNPq), à Fundação de Amparo à Pesquisa do Estado de Minas Gerais (FAPEMIG) e à Fundação de Ensino e Pesquisa em Medicina Veterinária e Zootecnia (FEP-MVZ) pelo suporte financeiro. F.M.C., A.P.L. e M.B.H. agradecem ao CNPq pela bolsa.

\section{REFERÊNCIAS}

Acres S.D. 1985. Enterotoxigenic Escherichia coli infections in newborn calves: a review. J. Dairy Sci. 68:229-256.

Aidar-Ugrinovich L., Blanco J., Blanco M., Blanco J.E., Leomil L., Dahbi G., Mora A., Onuma D.L., Silveira W.D. \& De Castro A.F.P. 2007. Serotypes, virulence genes, and intimin types of Shiga toxin-producing Escherichia coli (STEC) and enteropathogenic E. coli (EPEC) isolated from calves in São Paulo, Brazil. Int. J. Food Microbiol. 115:297-306.

Alberts B., Johnson A., Lewis J., Raff M., Roberts K. \& Walter P. 2010. Biologia Molecular da Célula. 5a ed. Artmed, Porto Alegre. 1396p.

Andrade G.I., Coura F.M., Santos E.L., Ferreira M.G., Galinari G.C., Facury Filho E.J., de Carvalho A.U., Lage A.P. \& Heinemann M.B. 2012. Identification of virulence factors by multiplex PCR in Escherichia coli isolated from calves in Minas Gerais, Brazil. Trop. Anim. Health Prod. 44:17831790.

Bardiau M., Szalo M. \& Mainil J.G. 2010. Initial adherence of EPEC, EHEC and VTEC to host cells. Vet. Res. 41:57-72.

Bartels C.J., Holzhauer M., Jorritsma R., Swart W.A.J.M. \& Lam T.J. 2010. Prevalence, prediction and risk factors of enteropathogens in normal and non-normal faeces of young Dutch dairy calves. Prev. Med. Vet. 93:162169.

Blanchard P.C. 2012. Diagnostics of dairy and beef cattle diarrhea. Vet. Clin. North Am. Food Anim. Pract. 28:443-464.

Blanco M., Blanco J.E., Mora A. \& Blanco J. 1998. Prevalence and characteristics of necrotoxigenic Escherichia coli CNF1+ and CNF2+ in healthy cattle. Res. Microbiol. 149:47-53.

Blumenthal B., Hoffmann C., Aktories K., Backert S. \& Schmidt G. 2007. The cytotoxic necrotizing factors from Yersinia pseudotuberculosis and from Escherichia coli bind to different cellular receptors but take the same route to the cytosol. Infect Immun. 75:3344-3353.

Boquet P. 2001. The cytotoxic necrotizing factor 1 (CNF1) from Escherichia coli. Toxicon 39:1673-1680.

Buchanan R.L. \& Doyle M.P. 1997. Foodborne disease significance of Escherichia coli 0157:H7 and other enterohemorrhagic E. coli. Food Technol. 51:69-76.

Burns A.L., Ball H.J. \& Finlay D.A. 1996. CNF producing Escherichia coli isolated from cattle in Northern Ireland. Vet. Microbiol. 49:235-241.

Butler D.G. \& Clarke R.C. 1994. Diarrhea and dysentery in calves, p.91-116. In: Gyles C.L. (Ed.), Escherichia coli in Domestic Animals and Humans. CABI Publishing, Walingford.

Caselani K. 2010. Avaliação dos controles microbiológicos e do programa de redução de patógenos no abate de bovinos. Dissertação de Mestrado em Medicina Veterinária, Faculdade de Ciências Agrárias e Veterinárias, 
Universidade Estadual Paulista "Júlio de Mesquita Filho", Jaboticabal, SP. $123 p$.

Centers for Disease Control and Prevention 2013. Outbreak of Escherichia coli 0104:H4 infections associated with sprout consumption - Europe and North America, May-July 2011. MMWR 62:1029-1031.

Cerqueira A.M.F., Guth B.E.C., Joaquim R.M. \& Andrade J.R.C. 1999. High occurence of Shiga toxin-producing Escherichia coli (STEC) in healthy cattle in Rio de Janeiro State, Brazil. Vet. Microbiol. 70:111-121.

China B., Pirson V. \& Mainil J. 1998. Prevalence and molecular typing of attaching and effacing Escherichia coli among calf populations in Belgium. Vet. Microbiol. 63:249-259.

Clements A., Young J.C., Constantinou N. \& Frankel G. 2012. Infection strategies of enteric pathogenic Escherichia coli. Gut Microbes 3:71-87.

Coura F.M. 2011. Estudo longitudinal prospectivo da incidência de enteropatógenos em bezerras em uma propriedade leiteira. Dissertação de Mestrado em Ciência Animal, Escola de Veterinária, Universidade Federal de Minas Gerais, Belo Horizonte, MG. 48p.

Croxen M.A. \& Finlay B.B. 2010. Molecular mechanisms of Escherichia coli pathogenicity. Natl Rev. Microbiol. 8:2638.

De Rycke J., González E.A., Blanco J., Oswald E., Blanco M. \& Boivin R. 1990. Evidence for two types of cytotoxic necrotizing factor in human and animal clinical isolates of Escherichia coli. J. Clin. Microbiol. 28:694-699.

De Rycke J., Milion A. \& Oswald E. 1999. Necrotoxigenic Escherichia coli (NTEC): two emerging categories of human and animal pathogens. Vet. Res. 30:221-233.

DeBroy C. \& Maddox C.W. 2001. Identification of virulence attributes of gastrointestinal Escherichia coli isolates of veterinary significance. Anim. Health Res. Rev. 2:129-140.

Foster D.M. \& Smith G.W. 2009. Pathophysiology of diarrhea in calves. Vet. Clin. North Am. Food Anim. Pract. 25:13-36.

Girard F., Dziva F., Van Diemen P., Philips A.D., Stevens M.P. \& Frankel G. 2007. Adherence of enterohemorrhagic Escherichia coli 0157, 026, and 0111 strains to bovine intestinal explants ex vivo. Appl. Environ. Microbiol. 73:3084-3090.

Güler L., Gündüz K. \& Ok Ü. 2008. Virulence factors and antimicrobial susceptibility of Escherichia coli isolated from calves in Turkey. Zoonoses Publ. Health 55:249-257.

Gyles C.L. \& Fairbrother J.M. 2010. Escherichia coli, p.231-265. In: Gyles C.A., Prescott J.F., Songer J.G. \& Thoen C.O. (Eds), Pathogenesis of Bacterial Infections in Animals. Wiley-Blackwell, Iowa.

Gyles C.L. 2007. Shiga toxin-producing Escherichia coli: an overview. J. Anim. Sci. 85:45-62.

Holland R.E., Wilson R.A., Holland M.S., Yuzbasiyan-Gurkan V., Mullaney T.P. \& White D.G. 1999. Characterization of eae ${ }^{+}$Escherichia coli isolated from healthy and diarrheic calves. Vet. Microbiol. 66:251-263.

Hopkins A.M., Walsh S.V., Verkade P., Boquet P. \& Nusrat A.A. 2003. Constitutive activation of Rho proteins by CNF-1 influences tight junction structure and epithelial barrier function. J. Cell Sci. 116:725-742.

Irino K., Kato M.A.M.F., Vaz T.M.I., Ramos I.I., Souza M.A.C., Cruz A.S., Gomes T.A.T., Vieira M.A.M. \& Guth B.E.C. 2005. Serotypes end virulence markers of Shiga toxin producing Escherichia coli (STEC) isolated from dairy cattle in São Paulo State, Brazil. Vet. Microbiol.105:29-36.

Johnson T.J., DebRoy C., Belton S., Williams M.L., Lawrence M., Nolan L.K. \& Thorsness J.L. 2010. Pyrosequencing of the Vir plasmid of necrotoxigenic Escherichia coli. Vet Microbiol. 144(1-2):100-9.

Kaper J.B., Nataro J.P. \& Mobley H.L.T. 2004. Pathogenic Escherichia coli. Natl Rev. Microbiol. 2:123-138.

Knust Z. \& Schmidt G. 2010. Cytotoxic Necrotizing Factors (CNFs): a growing toxin family. Toxins 2:116-127.

Lage A.P., Carvalho A.C.T., Leite R.C., Yano T. \& Serafim M.B. 1993. Toxigenic Escherichia coli in calves with diarrhea in Minas Gerais, Brazil. Arq. Bras. Med. Vet. Zootec. 45:352-359.

Langoni H., Linhares A.C., Avila F.A., da Silva A.V. \& Elias A.O. 2004. Contribution to the study of diarrhea etiology in neonate dairy calves in São Paulo State, Brazil. Braz. J. Vet. Res. Anim. Sci. 41:313-319.
Leomil L., Aidar-Ugrinovich L., Guth B.E., Irino K., Vettorato M.P., Onuma D.L. \& De Castro A.F. 2003. Frequency of Shiga toxin-producing Escherichia coli (STEC) isolates among diarrheic and non-diarrheic calves in Brazil. Vet. Microbiol. 97:103-109.

Mainil J. 2013. Escherichia coli virulence factors. Vet. Immunol. Immunopathol. 152:2-12.

Mainil J.G. \& Daube G. 2005. Verotoxigenic Escherichia coli from animals, humans and foods: who's who? J. Appl. Microbiol. 98:1332-1344.

Mendonça C.L., Lazaro N.S., Castro R.S., Afonso J.A.B. \& Hofer E. 1996. Occurrence of enterotoxigenic Escherichia coli and Salmonella sp. in calves in the southern Agreste region of the State of Pernambuco, Brazil. Pesq. Vet. Bras. 16:127-131.

Moura C., Ludovico M., Valadares G.F., Gatti M.S.V. \& Leite D.S. 2012. Detection of virulence genes in Escherichia coli isolated from diarrheic and healthy feces of dairy calves in Brazil. Arq. Inst. Biológico79:273-276.

Nagy B. \& Fekete P.Z. 2005. Enterotoxigenic Escherichia coli in veterinary medicine. Int. J. Med. Microbiol. 295:443-454.

Nataro J.P. \& Kaper J.B. 1998. Diarrheagenic Escherichia coli. Clin. Microbiol. Rev. 11:142-201.

Oliveira Filho J.P., Silva D.P.G., Pacheco M.D., Mascarini L.M., Ribeiro M.G., Alfieri A.A., Alfieri A.F., Stipp D.T., Barros B.J.P. \& Borges A.S. 2007. Diarréia em bezerros da raça Nelore criados extensivamente: estudo clínico e etiológico. Pesq. Vet. Bras. 27:419-424.

Oliveira M.G., Brito J.R., Gomes T.A.T., Guth B.E.C., Vieira M.A.M., Naves Z.V.F., Vaz T.M.I. \& Irino K. 2008. Diversity of virulence profiles of Shiga toxin-producing Escherichia coli serogroups in food-producing animals in Brazil. Int. J. Food Microbiol. 127:139-46.

Orden J.A., Domínguez-Bernal G., Martínez-Pulgarín S., Blanco M., Blanco J.E., Mora A., Blanco J., Blanco J. \& De La Fuente R. 2007. Necrotoxigenic Escherichia coli from sheep and goats produce a new type of cytotoxic necrotizing factor (CNF3) associated with the eae and ehxA genes. Int. Microbiol. 10:47-55.

Orden J.A., Ruiz-Santa-Quiteria J.A., Cid D., García S. \& De La Fuente R. 1999. Prevalence and characteristics of necrotoxigenic Escherichia coli (NTEC) strains isolated from diarrhoeic dairy calves. Vet. Microbiol. 66:265-273.

Pohl P., Oswald E., Van Muylem K., Jacquemin E., Lintermans P. \& Mainil J. 1993. Escherichia coli producing CNF1 and CNF2 cytotoxins in animals with different disorders. Vet. Res. 24:311-315.

Radostits O.M., Gay C.C., Hinchcliff K.W. \& Constable P.D. 2007. Veterinary Medicine: a textbook of the diseases of cattle, horses, sheep, pigs and goats. Elsevier, Philadelphia. 2156p.

Rigobelo E.C., Gamez H.J., Marin J.M., Macedo C., Ambrosin J.A. \& Ávila F.A. 2006. Virulence factors of Escherichia coli isolated from diarrheic calves. Arq. Bras. Med. Vet. Zootec. 58:305-310.

Salvadori M.R., Valadares G.F., Da Silva Leite D., Blanco J. \& Yano T. 2003. Virulence factors of Escherichia coli isolated from calves with diarrhea in Brazil. Braz. J. Microbiol. 34:230-235.

Salvarani S., Tramuta C., Nebbia P. \& Robino P. 2012. Occurrence and functionality of cycle inhibiting factor, cytotoxic necrotizing factors and cytolethal distending toxins in Escherichia coli isolated from calves and dogs in Italy. Res. Vet. Sci. 92:372-377.

Stordeur P., China B., Charlier G., Roels S. \& Mainil J. 2000. Clinical signs, reproduction of attaching/effacing lesions, and enterocyte invasion after oral inoculation of an 0118 enterohaemorrhagic Escherichia coli in neonatal calves. Microbes Infect. 2:17-24.

Van Bost S., Bâbe M.H., Jacquemin E. \& Mainil J. 2001a. Characteristics of necrotoxigenic Escherichia coli isolated from septicemic and diarrheic calves between 1958 and 1970. Vet. Microbiol. 82:311-320.

Van Bost S., Roel S. \& Mainil J. 2001b. Necrotoxigenic Escherichia coli type2 invade and cause diarrhoea during experimental infection in colostrum-restricted newborn calves. Vet. Microbiol. 81:315-329.

Van Bost S., Roels S., Oswald E. \& Mainil J. 2003. Putative roles of the CNF2 and CDTIII toxins in experimental infections with necrotoxigenic Escherichia coli type 2 (NTEC2) strains in calves. Microbes Infect. 5:1189-1193. 